Volume-V, Issue-02, July-December, 2010

\title{
Online Marketing in Bangladesh: A Descriptive Study in the Context of Some Selected Click and Mortar Businesses
}

\author{
MD. KAMRUL HASSAN ${ }^{1}$ \\ MD. ABDUL MOMEN ${ }^{2}$ \\ SEYAMA SULTANA ${ }^{3}$
}

\begin{abstract}
Every business requires a good marketing mix to introduce, grow, and sustain in this highly competitive marke economyt. At The day before yesterday marketers were rarely looking at online based marketing efforts, instead, they were just relaying on conventional marketing mix. With the presence of highly growing Internet users, relative low cost and easy going strategies, 'online marketing' is also becoming so crucial for every business hub. By getting the balance of offline and online advertising right, marketing mix will help provide everything firms need to gain leads, increase sales, improve customer retention, and rocket the company profits. The study has a comprehensive perspective and provides a bird's eye view of the online marketing practice in Bangladesh. This discussion is extended with an examination of the studies that compare conventional marketing practices with the principles and rules of the online marketing world particularly the four major components of the traditional marketing mix in an online context. To understand the online marketing environment in the country a greater sense of the study has extended its overall views from both the consumers and business perspectives. This study provides an effort to understand the relationship between online marketing exercise and the area of business operation (international vs. domestic) as well as gives an idea why marketers use Internet in the country. And this paper concludes with the prime exercise of online marketing which is centralizing mostly for leveraging international business operations in Bangladesh.
\end{abstract}

Keywords: Online Marketing, Online Marketing Mix, E-commerce, Click and Mortar Business

\footnotetext{
${ }^{1}$ Lecturer, Department of Tourism and Hospitality Management, University of Dhaka, Bangladesh

${ }^{2}$ Lecturer, Department of Business Administration, Northern University, Bangladesh

${ }^{3}$ Lecturer, Department of Business Administration, Northern University, Bangladesh
} 


\section{INTRODUCTION}

The introduction and transmission of the Internet phenomenon into the business arena guiding the marketing discipline to various changes and strong challenges. Since the revolution of online based market marketing practice has been busy with integrating the potential of information and communication technologies through the utilization of databases and online marketing. Billions of potential consumers can now be reached this way. In recent times, online marketing has secured its place as the preferred marketing method. For an industry that emerged only within the past decade or so, online marketing has gained popularity quickly. It is now attracts a greater portion advertising dollar than any other media type, including TV, Radio, Print and others. For business to stay ahead, or perhaps even stay in the game, marketers need to have an effective online marketing strategy. Online marketing provides a new force of attracting more quality sales leads, increasing business revenue, enhancing business profitability, improving business sustainability in the competitive global market.

Online marketing also referred to as i-marketing, web marketing, Internet marketing, or e-marketing, is the use of the Internet to advertise and sell products and services. Within the definition of Online Marketing people will find mention of pay per click advertising, banner ads, e-mail marketing, search engine marketing (including search engine optimization), blog marketing, and article marketing. Each of these subject areas is important to consider prior to planning suitable internet marketing strategy. A website and online presence is one aspect of the marketing mix for a business. For the small to medium business, there is no reason for a website to be the sole method of marketing - but by integrating a website into marketing plan organization can drive new leads and generate new business that wouldn't ordinarily reach using a single avenue of advertising.

To outline e-promotion includes: Banner promotion, Web public relations (WPR), E-leaflets and having a domain name. The e-marketing mix must work together and support each other if the company is to have a successful online marketing strategy. So just as when marketing in the offline world, keeping online marketing mix balanced using a combination of immediate traffic generation, midterm strategies and long-term targeted traffic magnets. With a good balance marketers can have a good launch, and then continue to see sales from that product, service or affiliate marketing promotion for sometime to come as turn focus to next money-making opportunity. So e-commerce has grown by leaps and bounds and continues to set new marks every year.

Online marketing is attractive because it levels the playing field for all competitors, big and small. Dominant brick and mortar companies use marketing 
firms to push their brands on television, billboards, magazines, and so on. When the companies open a site, they often have these marketing firms handle their internet efforts as well. Crushing them on search engines is like taking candy from a baby. They haven't a clue what they are doing, but their superiority will never let them acknowledge they are paying triple the going rate for advertisements on high traffic sites. Unlike 'click only' and 'brick and mortar' and 'click and mortar' cover marketing effort both in conventional and online arenas. Since the inter connection with information with information super highway click and mortar becomes the crucial path to be flourished for a conventional business entity.

\section{Attaching Online Marketing into Marketing Mix}

The online version of the marketing mix is basically the same, but is applied differently. This paper demonstrates some of the twists and turns of applying the marketing mix to online situations. Website itself can be a product or a means of promotion. If website is simply promoting firm's product it is possible to skip this element of the marketing mix when thinking about website. Say for an example, if firms use websites to promote their off-line product then website is not a product. On the other hand, if firms use a Question and Answer section in the websites to help prospects then web site has just become part of the product element of the marketing mix. Company needs to develop a product (website) that offers some kind of unique value desired by target market. This could be niche content, an interesting application or another form of value. This is the element that kills many website since there is often no true value add for the target market. Distribution online is becoming a lot more interesting today. Web content was once limited to simple reading or online purchases. Now, online distribution can become convoluted quickly. One can choose from widgets, RSS, XML, downloads, RDF, and off-line combinations. Taking decision of online distribution depends on the nature of products, type of business, customer preferences, or what channels do marketers want product to be seen in. As more technology is developed for distributing content, these decisions will only become more difficult. The primary considerations for traditional, off-line business-to-consumer organizations involve consumer convenience and image. Where business is located will have a lot to do with how brand is perceived. The sharper image is a whole different business when stick it in the wrong place. Online distribution could overcome this difficulty. Web pricing may vary from traditional Brick and Mortar Company. Here most important thing is the time of user needs to spend on company's site equal the amount of value the company provides. This element is most like the off line counterpart. However, a lot of online marketers are missing a lot of the tools traditional marketers use. Online marketing campaign may suffer form several challenges. Those are lack of a 
core message, inconsistency, lack of sequence, not following database marketing strategies.

Using Web Address (Website) can act as a point of reference for all of firm's leads and existing customers. Include web address in all forms of offline communication. If firms post physical products, ensure that the packing slips and invoices have the URL of website in a prominent position. Website itself can be used to answer many questions that customers might have, reducing the time and even resource needed to respond to problems and questions posed by buyers. With any form of advertising it is vital to optimize web landing pages. Optimizing a landing page means providing the content that visitors expect. Firms should direct visitors to the most appropriate page on website to answer their questions or to make a sale. If firms use direct mail advertising and are promoting a specific product then direct visitors to the purchase page for that product. If they are offering your website as a place to get answers to questions or to resolve issues, direct them to the knowledge base or customer service page. Marketers could use online advertising to advertise offline business. While some businesses are run predominantly online, many websites are used to promote a bricks-and-mortar business. Whatever the purpose of business, a website usually offers some form of advantage. The Internet is a global marketplace and provides a genuinely affordable method to promote even the smallest business. Very few other methods level the playing field so clearly between small businesses and large corporations. Newspaper and radio advertising provide a very direct form of marketing. Few websites can realistically afford television advertising but flyers, direct mail, and less expensive advertising methods are a genuinely viable alternative. Again, the key to success in using these forms of advertising is integrating them within online marketing mix. Only through good integration, directing visitors to the most appropriate page, and optimizing that landing page.

There is one very effective way to pursue brand marketing online. Creating an image for a product sounds like so much fun, particularly when one doesn't have to show a particular advertisement produced exactly particular amount of sales. On the Internet, marketers should always be able to show such a revenue analysis correctly. Online marketers that promote branding services, there is one area where marketers can establish a branding element. This area is known as article publication and distribution. Traditionally, this marketing strategy has been used as part of a search engine optimization strategy, but it works for branding as well. The Internet is all about the flow of free information. There are millions of sites on the web and they are all looking for new content to keep their visitors coming back. This is where articles and article directories come in. An article directory is a site where writers 
publish articles that other sites can use without worrying about copyright issues. In exchange, the sites agree to publish the authors name and an author byline. The situation is similar to writing a column for local newspaper, except writing for hundreds or thousands of newspapers depending on the number of sites that pick up your articles. To take advantage of these directories, marketers need to write articles on subjects relevant to their business. The articles are not press releases nor should they be sales pitches. They are information articles and should offer something luscious. So, how does this constitute brand marketing online? It establishes marketers and their business as credible source on a subject. If it is possible to publish hundreds of articles regarding the industry in the directories, it can expect that the site will become the dominant site in the industry. By publishing quality articles in the directories, marketers can create strong and powerful brand.

As the Internet has expanded, so have the opportunities for marketing online. Here it would take a brief look at each type of Internet marketing and explain the benefits of each to have insides of online marketing tactics. Different sites like Google offer pay-per-click advertising for anyone interested in getting their message in front of the right segment or prospective buyer. This method is highly targeted and offers one of the best and most popular forms of internet marketing. Marketers using pay-per-click advertising only pay a fee, based on the competitiveness of a keyword or ad title, when a link is clicked on. Once the king of Internet marketing, online banner ads have developed to include animated and flash banners, but the premise remains largely the same. Marketers purchase a specified number of impressions to run on a single site or network of sites and are generally not guaranteed a specific number of clicks. Effective among current clients and prospects who have requested information form of the company, email marketing is a well established means to communicate and marketing products. If marketers want web browsers to visit their sites, than focusing on search engine optimization and search engine marketing is a must. No Internet marketing plan is complete without ensuring that the site is submitted and included on major directories like Google, Yahoo!, and DMOZ. Getting mention of company's site or information related to products can quickly scale if able to effectively tap into the countless blogs that are being created everyday. It is essential to focus company's efforts on blogs covering topics relevant to the product or service offering. One of the most important aspects of Internet Marketing is to improve the link popularity to your site and improve the awareness of product or service offering. To do so, many companies are focusing on publishing valuable content and making available for other to post to their websites.

There are many advantages to having a fully executable internet marketing strategy. These benefits include measurability, flexibility, and affordability. Many 
online marketing tactics provide marketing professionals with the ability to customer acquisition costs. Moreover, marketing professionals are better able to track what marketing campaigns are working and quickly allocate their spending towards higher producing media placements.

\section{Literature Review}

So far it is possible to identify, a large number of research studies on the subject of online marketing has been done throughout the world. But it is difficult to find out papers that only highlight online marketing practices in Bangladesh. For having a close idea about online marketing and its supportive activates it could be helpful to go through different studies of foreign and domestic articles and research papers. This study is an attempt to organize and summarize the literature about Internet marketing particularly online marketing and enlighten the research routes that will contribute to the advancement of the discipline.

The World Wide Web is an important marketing medium and to gain success in this arena a marketer should have well planned online marketing strategy (Malhotra, 2008). Consumers are expected to become more accustomed to the online shopping environment in the near future as most studies commonly project. The risks they currently perceive are likely to decline and this will increase the variety of goods being purchased from the Web market. One very profitable and useful re-search stream would be to identify which products will make a leap in terms of the online selling potential they carry for the near future. As customers usually lack foresight about their own needs and cannot make ac-curate long-run forecasts of their own behavior (Harari, 1999), it is the task of researchers to find this out and open the road for marketers who want to invest in the future B2C market on the Web.

Among the various routes marketers take to differentiate themselves on the Internet market, economic pricing is receiving heightened attention. With the increasing use of price search services, price wars are becoming bloodier than they are in the retail arena. On the other hand, some businesses still prefer to differentiate themselves based on other factors like product quality or support services such that offerings are not directly price comparable (Dickson, 2000).

A very common discussion in the e-marketing literature is that disintermediation will be widespread and electronic markets will automatically reduce the need for brokers (Gallaugher, 1999; Choudhury et al., 1998). It is possible to argue that the Web market can really fulfill most of the four specific missions of retailers: bringing the right product, at the right place, at the right price, and at the right time (Christensen and Tedlow, 2000) with the time function remaining as an exception for physical offerings. With this point of view, the 
number and functions of intermediaries may be expected to decrease substantially in this revolutionary medium.

With the additional online promotions, more people are going to turn to internet shopping in order to save time and money (Pelt, 2006). Internet marketing also refers to the placement of media along different stages of the customer engagement cycle through search engine marketing (SEM), search engine optimization (SEO), banner ads on specific websites, e-mail marketing, and Web 2.0 strategies (Story, 2008). The effect on the advertising industry itself has been profound. In just a few years, online advertising has grown to be worth tens of billions of dollars annually (James, 2007).

In an article titled as "Discover the 4 P's of Internet Marketing Mix", Lee (2009) states Internet changes the way of selling products and services in comparison to traditional marketing mix. Consumers now use the internet to research and purchase products/services online. Organization now needs online strategies to attract and retain customers. The e-marketing mix considers the elements of presenting the marketing mix online. Online, this immediate tangibility disappears. He also identifies the grounds why E-commerce sales are increasing at extremely high rates. Firstly there are clear online facts about the product customers are purchasing. The buyer knows immediately about product features, the facts, not sales persons assumptions. The buying process is also customized for returning visitors, making repeat purchases easier. Organizations can also offer immediately ancillary products along with the main purchase. As mentioned in marketing mix section, pricing is always difficult to do and must take into account many considerations. Traditionally pricing was about finding about customer's costs, discovering how much consumers are willing to pay, taking account competition pricing then setting your price. The internet has made pricing very competitive. Many costs i.e. store costs, staff cost have disappeared for complete online stores, placing price pressures on traditional retailers. The internet gives consumers the power to shop around for the best deal at a click of a button. Such easy access to information helps to maintain prices within the online world. E-pricing can also easily reward loyal customers. Technology allows repeat visitors to be tracked, easily allowing loyalty incentives to be targeted towards them. Payment is also easy online credit cards use allows for easy payments. One of the biggest changes to the marketing mix is online purchasing. Consumers can purchase direct from manufacturers cutting out retailers totally. The challenge for online retailers is to insure that the product is delivered to the consumer within a reasonable time. Location is important within place strategy. Online location can refer to where links are placed on other websites. Promoting products and service online is concerned 
with a number of issues. Having a recognizable domain name is first stage towards e-promotion. Most organizations today have some form of webpage used in most if not all advertisements. Placing banner advertisements on other web pages is a common form of e-promotion. Banner ads must be placed where potential customers browse. Web public relations are another approach to promoting online. News worthy stories based on product or service launches can be placed on the company's webpage, or WPR articles sent to review sites for consumers to read. Hopefully this form of online promotion will pull the consumer in. Direct email is a popular and common form of e-promotions. Organizations can send e-leaflets to hundreds and thousands of respondents, hoping a small percentage will reply.

Wilson (2002) says that a business can't rely on just one marketing approach, but must develop a whole spectrum of marketing strategies, operating simultaneously, in order to survive and flourish in a competitive world. Internet provides new type of opportunities if it is possible to develop an effective marketing mix. He also has said that many website owners pat themselves on the back if they can employ just a single Internet marketing strategy. But successful web and brickand-mortar businesses know that the key to success is developing a diverse marketing mix that works. He also provides some guidelines to develop marketing mix. Firstly creating the feelings of personal presence assists online marketing. Successful marketers are very aware of creating a personal presence or human attachment to greet visitors to their site. A photo, a personal word, a way to engage them in conversation or a free gift can provide superfluous feelings. Live chat is one of these tools. Other purposeful networking is done in e-mail discussion groups and mailing lists. Internet marketers are involved with their visitors, and are constantly finding ways to attract visitors' attention, and bring them into the site where they can be seated and begin to consider a purchase. Secondly he mentions that word of mouth (WOM) is a vital thing. Initially providing superior services or products is essential. Then using tell-a-friend boxes and send-this-page-to-a-friend scripts and encouraging subscribers to forward newsletter to a friend or associate is important in growing firm's subscriber list by word-of-mouse. Fliers to attract customers, simplified price structure, connecting Internet points, fliers to attract locals, referral fees, group pricing, are helpful to develop a fruitful marketing mix.

\section{OBJECTIVES OF THE STUDY}

The objective of this research is to provide an inside scenario about the online marketing efforts of different business marketers. Particularly the main objective of this study is to examine the extent of online marketing usually using by the click and mortar business in Bangladesh. The specific objectives of this study are: 
- To show the relationship between exercising online marketing and nature of business in different companies;

- To have an idea about which type of companies are using online marketing in Bangladesh;

- To classify the purposes of using Internet among the extent of exercising online marketing and identify specific online means those are used to connect with the customers.

\section{METHODOLOGY}

This study is basically quantitative in nature based on both secondary and primary data. Different national and international published literatures, journals, brochures, articles, researches, case studies etc. are followed for gathering data from secondary sources regarding online marketing. For collecting the primary data extensive survey is conducted. Employees or associates of different business organizations that are using Internet as means of supporting marketing mix were respondents of this study. Initially sample size for collecting primary data was 100 but for supporting the final analysis the sample size was reached at 120. To facilitate the interpretation of discriminant analysis the half of the sample represents business organizations those are practicing limited extent of online marketing and remaining half represents those business organizations that are practicing large extent of online marketing. For identifying the sample non-probability judgmental sampling technique is applied. The data were collected by using a self administered questionnaire from each respondent. The missing values coming from non-response of the survey were adjusted by using subjective estimates and trend analysis. The questionnaire was contained by several questions were finalized after pre-testing. Data collected using initial three questions are categorical in nature and data collected using six statements relating to the perceptions of the respondents on a five points Likert-type scale ranging from strongly disagree (1) to strongly agree (5) are interval in nature. The study was carrying out during the period from June 10, 2009 to April 15, 2010. Cross tabulation, descriptive statistics discriminant analysis and frequency distribution are used to examine the scenario of practicing online marketing by the click and mortar marketers in Bangladesh.

\section{Assumption of the Study}

It is difficult to find out a research work which is free from assumption. For every exclusive research, few assumptions will have to be constructed. The assumptions are made anticipating that the result will be as that of the presented objectives. 
- Structured questionnaire which is used to collect data through survey (personal interview) is accurate and simple.

- The research methodology of this study is appropriate.

- The sample size of 120 to analyze the scenario of online marketing is adequate and represents the population of the study.

\section{Analysis and Findings}

The Table 1 shows the relationship between extents of exercising online marketing and operation area of business (domestic \& international vs. domestic only operation). Among the 60 respondents who are practicing limited extent of online marketing 19 of those reported that their organizations have both domestic and international business operations and 41 of the respondents mentioned that their organizations involve only domestic business operation. On the other hand among the rest 60 respondents who are practicing large extent of online marketing 54 of confirmed that their organizations have both domestic and international business operations and merely 6 respondents reported that their organizations have only domestic business operations. Thus it is clear that online marketing become popular to operate business in international arena. Online marketing exercise is not considerable yet in domestic business operation in Bangladesh. From the chi square test (Table 2), it can be observed that the result is significant (at $\alpha=0.05$ ) indicating that there is difference between exercising online marketing limited extent and large extent in consideration of operation area of business.

TABLE 1

EXERCISING ONLINE MARKETING * OPERATION AREA OF BUSINESS CROSS TABULATION

\begin{tabular}{|c|c|c|c|c|c|}
\hline & & & \multicolumn{2}{|c|}{ Operation Area of Business } & \multirow[t]{2}{*}{ Total } \\
\hline & & & $\begin{array}{c}\text { Domestic and } \\
\text { International } \\
\text { Business }\end{array}$ & $\begin{array}{c}\text { Only } \\
\text { Domestic } \\
\text { Business }\end{array}$ & \\
\hline \multirow{4}{*}{$\begin{array}{l}\text { Exercising } \\
\text { Online } \\
\text { Marketing }\end{array}$} & Limited Extent & Count & 19 & 41 & 60 \\
\hline & & Expected Count & 36.5 & 23.5 & 60.0 \\
\hline & Large Extent & Count & 54 & 6 & 60 \\
\hline & & Expected Count & 36.5 & 23.5 & 60.0 \\
\hline \multirow[t]{2}{*}{ Total } & & Count & 73 & 47 & 120 \\
\hline & & Expected Count & 73.0 & 47.0 & 120.0 \\
\hline
\end{tabular}


TABLE 2

CHI-SQUARE TESTS

\begin{tabular}{lcc|c|c|c|c}
\hline & Value & df & $\begin{array}{c}\text { Asymp. Sig. } \\
(2 \text {-sided })\end{array}$ & $\begin{array}{c}\text { Exact Sig. } \\
(2 \text {-sided })\end{array}$ & $\begin{array}{c}\text { Exact Sig. } \\
(1 \text {-sided })\end{array}$ \\
\hline $\begin{array}{l}\text { Pearson Chi-Square } \\
\begin{array}{l}\text { Continuity } \\
\text { Correction (a) }\end{array}\end{array}$ & $42.845(\mathrm{~b})$ & 1 & .000 & -- & -- \\
$\begin{array}{l}\text { Likelihood Ratio } \\
\text { Fisher's Exact Test }\end{array}$ & 46.731 & 1 & .000 & -- & -- \\
$\begin{array}{l}\text { Linear-by-Linear } \\
\text { Association }\end{array}$ & 42.488 & 1 & .000 & -000 & .000 \\
N of Valid Cases & 120 & -- & -- & -- & -- \\
\hline
\end{tabular}

Note: a. Computed only for a $2 \times 2$ table

b. 0 cells $(.0 \%)$ have expected count less than 5 . The minimum expected count is 23.50 .

The group statistics of the independent variables (Gathering information, Creating awareness, Providing customer service, Guiding sales, Accomplishing transaction, and Performing communication) in terms of categorical variable (Exercising Online Marketing) for measuring the reasons of using online marketing is presented in Table 3. This table shows the means, standard deviation and sample sizes for each variable in the two categories. It can see that all the means of exercising online marketing in limited extent differ noticeably from exercising online marketing in large extent. The variation is also observed in standard deviations of the groups. These differences will hopefully allow using these predictors to distinguish observations in one category to another category of exercising online marketing.

From the discriminant analysis, the output of classification matrix (Table 4) can be observed that the discriminant function, obtained is able to classify $70 \%$ of the 120 respondents correctly. Specifically it says that out of 60 cases predicted to be in 'limited extent' category, 40 were found to be in 'limited extent' and 20 in 'large extent'. Similarly out of 60 cases predicted to be in 'large extent', 44 were found to be in 'large extent' and 16 in 'limited extent'. Therefore, on the whole, 36 cases out of 120 were misclassified by the discriminant model, giving a classification (or prediction) accuracy level of $70 \%$. For the validity analysis of the classification matrix, the leave-one-out classifications classify $64.2 \%$ of the 120 respondents correctly. 
TABLE 3

GROUP STATISTICS

$\begin{array}{clccc}\begin{array}{c}\text { Exercising Online } \begin{array}{c}\text { Marketing } \\ \text { Limited Extent }\end{array} \\ \end{array} & \text { Gathering information } & \text { Std. Deviation } & \begin{array}{c}\text { Valid N } \\ \text { (Unweighted) }\end{array} \\ & \text { Creating awareness } & 3.7167 & 1.18023 & 60 \\ & \text { Providing customer service } & 2.8000 & .95314 & 60 \\ & \text { Guiding sales } & 2.7833 & 1.30308 & 60 \\ & \text { Accomplishing transaction } & 3.4167 & 1.02992 & 60 \\ \text { Large Extent } & \text { Performing communication } & 3.6333 & 1.13446 & 60 \\ & \text { Gathering information } & 3.9833 & .98276 & 60 \\ & \text { Creating awareness } & 4.3167 & .81286 & 60 \\ & \text { Providing customer service } & 3.6500 & 1.31259 & 60 \\ \text { Guiding sales } & 3.7000 & 1.41780 & 60 \\ & \text { Accomplishing transaction } & 3.6833 & 1.15702 & 60 \\ & \text { Performing communication } & 3.7167 & 1.47397 & 60 \\ & \text { Gathering information } & 4.5000 & .81303 & 60\end{array}$

TABLE 4

CLASSIFICATION RESULTS (B, C)

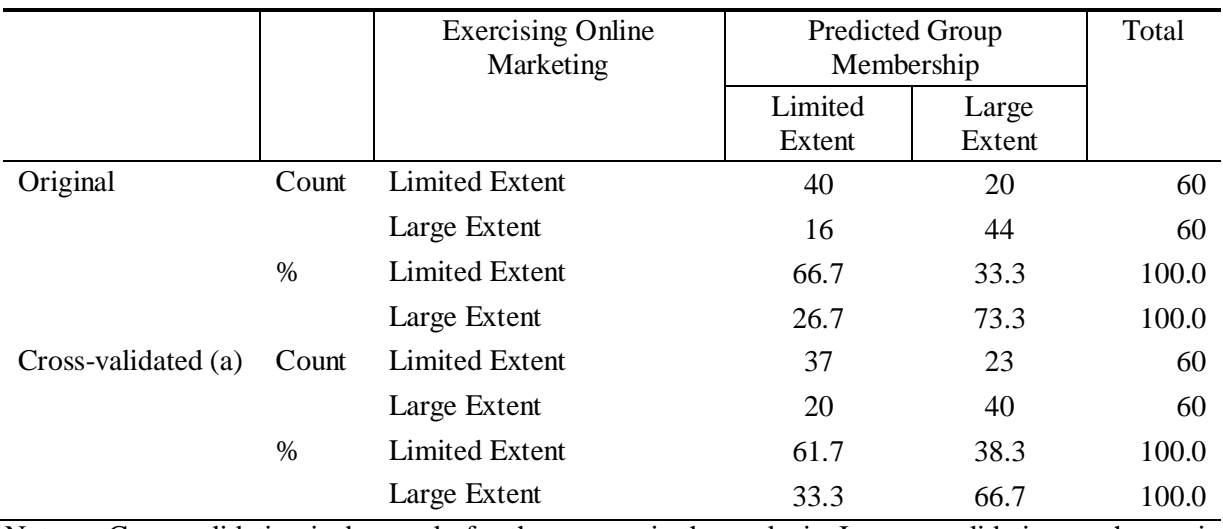

Note: a. Cross validation is done only for those cases in the analysis. In cross validation, each case is classified by the functions derived from all cases other than that case.

b. $70.0 \%$ of original grouped cases correctly classified.

c. $64.2 \%$ of cross-validated grouped cases correctly classified. 
The acquired level of accuracy may vary for all the future classification of exercising online marketing. But it is still a pointer towards the model being a good one, assuming the input data was relevant and scientifically collected.

The Eigenvalue (.304) has given in Table 5 shows the ration of the betweengroup sums of squares to the within-group sum so squares of the discriminant scores. The canonical correlation is simply the Pearson correlation between the discriminant function scores and group membership. Here canonical correlation value is .483 so that $.483 * .483 * 100=23.33 \%$ of the variances in the discriminant function scores can be explained by group differences.

TABLE 5

\section{EIGENVALUES}

\begin{tabular}{c|c|c|c|c}
\hline Function & Eigenvalue & $\begin{array}{c}\% \text { of } \\
\text { Variance }\end{array}$ & $\begin{array}{c}\text { Cumulative } \\
\%\end{array}$ & Canonical Correlation \\
\hline 1 & $.304(\mathrm{a})$ & 100.0 & 100.0 & .483 \\
\hline
\end{tabular}

Note: a. First 1 canonical discriminant functions were used in the analysis.

From the 'Chi-Square Test' with successive roots removed, the Wilk's Lambda was found to be 0.767 (Table 6). Since the value is bellow 1 indicates good discriminating power of the model. The significant level for the Chi-square test indicates that the discrimination between the two groups is highly significant.

TABLE 6

WILKS' LAMBDA

\begin{tabular}{c|c|c|c|c}
\hline $\begin{array}{c}\text { Test of } \\
\text { Function(s) }\end{array}$ & Wilks' Lambda & Chi-square & DF & Sig. \\
\hline 1 & .767 & 30.526 & 6 & .000 \\
\hline
\end{tabular}

In this study there are six independent variables. Those are Gathering information, Creating awareness, Providing customer service, Guiding sales, Accomplishing transaction, and Performing communication. Present study attempts to find out which of these is a better predictor of online marketing being exercised in limited extent or large extent. Here one thing should address that exercising online marketing in limited extent means having small infrastructure of online marketing in organizations those are performing very close to brick and mortar marketers. Conversely, exercising online marketing in large extent means having medium to huge infrastructure of online marketing in organizations those are 
performing very close to click only marketers. From the output table for 'Standardized coefficients for canonical variables' (Table 7), it was observed that 'creating awareness' is the best predicator with a coefficient of 0.548 , followed by 'providing customer service', with a coefficient of 0.509, 'gathering information' with a coefficient of 0.341 , 'performing communication' (0.292), and so on. Here one of the most vital points is that the absolute value of the standardized coefficient of each independent variable indicates its relative importance.

TABLE 7

STANDARDIZED CANONICAL DISCRIMINANT FUNCTION COEFFICIENTS

\begin{tabular}{l|c}
\hline & Function 1 \\
\hline Gathering information & .341 \\
Creating awareness & .548 \\
Providing customer service & .509 \\
Guiding sales & -.088 \\
Accomplishing transaction & -.037 \\
Performing communication & .292 \\
\hline
\end{tabular}

Classification of exercising online marketing in limited extent or large extent can be judged from the output table of raw coefficients for canonical variables and means of canonical variables. The means of canonical variable gives the new means for the transformed group Centroids. Thus the new mean for limited extent of exercising online marketing is -.547 and new mean for large extent of exercising online marketing is .547 (Table 8 ). This indicates that the midpoint of the two is 0 (zero). This also helps to reach at a decision rule for classifying online marketing exercise. If the discriminant factor of online marketing is negative, it will considered as 'limited extent' and if the discriminant factor of online marketing is positive, it will classify as 'large extent' of exercising online marketing.

TABLE 8

FUNCTIONS AT GROUP CENTROIDS*

\begin{tabular}{l|c}
\hline \multicolumn{1}{c|}{ Exercising Online Marketing } & Function 1 \\
\hline Limited Extent & -.547 \\
Large Extent & .547 \\
\hline
\end{tabular}

* Unstandardized canonical discriminant functions evaluated at group means 
TABLE 9

CANONICAL DISCRIMINANT FUNCTION COEFFICIENTS (UNSTANDARDIZED)

\begin{tabular}{l|c}
\hline & Function 1 \\
\hline Gathering information & .336 \\
Creating awareness & .478 \\
Providing customer service & .374 \\
Guiding sales & -.081 \\
Accomplishing transaction & -.028 \\
Performing communication & .323 \\
(Constant) & -5.085 \\
\hline
\end{tabular}

In order to compute the discriminant score of any new organization's online marketing exercise, the unstandardized discriminant function has to be used (Table 9). The discriminant score (D) can determine by using following linear combination function:

$$
\begin{aligned}
\mathrm{D}= & -5.085+\mathrm{g} \_ \text {info }(.336)+\mathrm{awar}(.478)+\text { cus_ser }(.374)-\mathrm{g} \_ \text {sales }(.081) \\
& -\mathrm{a} \_ \text {trans }(.028)+\mathrm{p} \_ \text {comm }(.323)
\end{aligned}
$$

If it is possible to get information about gathering information, creating awareness, providing customer service, guiding sales, accomplishing transaction, performing communication over Internet to support marketing mix of a business organization, then the above discriminant function gives the score that helps to classify other organizations whereas they are exercising limited extent or large extent of online marketing.

\section{Limitations of the Study}

In spite of providing a clear inside notion regarding the online marketing of the click and mortar business in Bangladesh, this study suffers from several limitations.

- Lack of access to the appropriate individual in some cases of data collection through personal interview survey.

- Sample size is too small in consideration of actual population.

- $\quad$ Non-probability sampling technique has been applied in sampling process as it is difficult to define the exact population of the study by limited effort.

- The total research has been conducted in a short span of time.

\section{CONCLUSION}

As online marketing is a new concept in Bangladesh, many marketers still don't realize its importance and application. Some business organizations that have 
international business operations are exercising online marketing partially. Many business firms in Bangladesh those are high tax payers even don't have a web site. The businesses that only serve the domestic market have limited online marketing endeavor. Lack of customers' accessibility over Internet is the major setback of growing online marketing. Some brick and mortar companies changing themselves as click and mortar companies to enjoy competitive advantage. Without some auction companies and job sites it is difficult to find out pure click only companies in Bangladesh.

It is not possible always to apply real world marketing practices to online marketing. Online marketing tends to be an entirely different challenge. Strategic online marketing is necessary to success on web. In fact, most of the businesses people who are on the Internet say that they use it mainly for gathering information in Bangladesh. High speed Internet accessibility is necessary to boost the online marketing practice throughout the country. This study basically measure extent of practicing online marketing of different type of business firms in Bangladesh presently.

\section{REFERENCES}

Christensen, Clayton M., and Richard S. Tedlow, (2000): "Patterns of Disruption in Retailing." Harvard Business Review 78 (1): 442.

Choudhury, Vivek, Kathleen S. Hartzel, and Benn R. Konsynski. (1998): "Uses and Consequences of Elec-tronic Markets: An Empirical Investigation in the Aircrafts Parts Industry." MIS Quarterly 22 (4): $p 471$.

Dickson, Peter R.. (2000): "Understanding the Trade Winds: The Global Evolution of Production, Con-sumption, and the Internet." Journal of Consumer Research 27 (June)

Gallaugher, John. (1999): "Challenging the New Conventional Wisdom of Net Commerce Strategies." Communications of the ACM 42 (7): p27.

Harari, Oren (1999): “Obsolete.com?" Management Review (September): p31.

James, David People Magazine Time, Inc. February 24, 2007 "Bid on Dreamgirls Costumes for Charity"

Lee, Richard (January, 2009): "Discover the 4 P's of Internet Marketing Mix", Source: http://www.duyud.com/discover-the-4-ps-of-internet-marketing-mix

Malhotra, Vikas (2008): "Best Place for Online marketing strategies" Article Source: http://www.articlesnatch.com

Pelt, Jackie Van (2006): "Online Marketing Heats up Holiday Retailing”, Source of the Article: $h t t p: / / w w w . t e c h w e b . c o m / w i r e / e b i z / 193104234$

Story, Louise and comScore (March 10, 2008): "They Know More Than You Think" (JPEG).http://www.nytimes.com/imagepages/2008/03/10/technology/20080310_PRIV ACY_GRAPHIC.html.

Wilson, Dr. Ralph F. (2002): "Developing an Effective Marketing Mix", Web Marketing Today, Issue 111, April 11, 2002 